altering the psychological component provides a simple and brief way to overcome a troublesome situation.

The goal of psychiatrists should be to help patients to understand the nature of their problems and to weigh the benefits and the costs of the available therapeutic alternatives. In order to do this it is appropriate for psychiatrists to have an adequate working knowledge about each of the currently available forms of intervention, its indications and contra indications, so that therapy can be tailored to suit the needs of individual patients rather than trying to fit the patient into the mode of therapy which is convenient to the therapist. Hypnotherapy should be considered as a supportive and supplementary therapy and not as a substitute form of therapy to treat the untreatable.

\section{Acknowledgements}

I wish to thank Dr S. Bhaumik and Dr D. Bramble for their contribution to this paper.

\section{References}

Barber, T. X. (1963) The effects of hypnosis on pain: a critical review of experimenal and clinical findings. Psychological Medicine, 25, 303-333.

- (1965) The effect of hypnosis on learning and recall: a methodological critique. Journal of Abnormal Psychology, 21, 19-25.

BraID, J. (1843) Neurypnology London: Churchill.

Hilgard, E. R. (1977) Divided consciousness: multiple controls in human thought and action. New York: WileyInterscience.

LIEBEAULT, A. A. (1866) Du sommeil et des etats analogues consideres surtout au point de vue de l'action du moral sur le physique. Paris: Masson.

ORNe, M. T. \& Evans, F. J. (1965) Social control in the psychological experiment: antisocial behavior and hypnosis. Journal of Personality and Social Psychology, 1, 189-200.

Waxman, D., Pedersen, D., Wilkie, I. \& Mellett, P. (1989) Hypnosis: The Fourth European Congress at Oxford. London: Whurr Publishers.

A full list of references is available on request from $\mathrm{Dr}$ Mathew.

Psychiatric Bulletin (1993), 17, 204-206

\title{
The Access to Health Records Act: what difference does it make?
}

\author{
Robert E. Butler, Registrar, Department of Child and Adolescent Psychiatry; and \\ DASha E. Nicholls, Registrar, Department of Psychiatry, University College \\ Hospital and Middlesex School of Medicine, London W1N 8AA
}

\begin{abstract}
The Access to Health Records Act came into force on 1 November 1991. This legislation allows patients access to their written medical records (access to computerised records is covered by separate legislation). Concerns have been expressed about the implications of this Act for staff and patients, particularly in psychiatry. These concerns have included detrimental effects on patients exposed to their notes and the restrictions it could place upon staff in recording speculation or subjective opinion. We report the following findings: staff attitudes to the new legislation including awareness of the Act, evaluation of the Act as useful or detrimental and the Act's implications on clinical practice.
\end{abstract}

\section{The study}

A 70 item questionnaire was sent to all full-time qualified staff working in the department of psychiatry in a district general hospital (Princess Alexandra Hospital, Harlow, Essex $)(n=102)$.

The questionnaire was developed following a pilot study with two earlier versions. It is designed to assess staff attitudes to The Access to Health Records Act and includes issues raised both in the Danish literature (Svendsen \& Toftegaard, 1989; Andersen \& Jorgensen 1989) and English literature (Bernadt et al, 1991; McShane et al, 1992). The questionnaire includes open and closed questions. 
TABLE I

Differences across staff groups

\begin{tabular}{|c|c|c|c|c|c|}
\hline & \multicolumn{2}{|c|}{ Doctors } & \multicolumn{2}{|c|}{ Nurses } & \multirow[t]{2}{*}{$\chi^{2}$} \\
\hline & $A$ & $D$ & $A$ & $D$ & \\
\hline \multicolumn{6}{|l|}{ The Act: } \\
\hline (1) Makes staff write more accurate notes & 6 & 7 & 31 & 7 & $4.45^{*}$ \\
\hline (2) Makes staff discuss more with their patients & 7 & 6 & 33 & 5 & $4.44^{*}$ \\
\hline (3) Makes staff think more about their management & & & & & \\
\hline of patients & 3 & 11 & 29 & 13 & $7.87^{* *}$ \\
\hline (4) Improves patients' compliance with treatment & 0 & 11 & 11 & 14 & $5.05^{*}$ \\
\hline (5) Makes staff write more legible notes & $\mathbf{0}$ & 12 & 22 & 18 & $9.30^{* *}$ \\
\hline (6) Has had an effect on your presentation of notes & 0 & 16 & 21 & 18 & $11.75^{* * *}$ \\
\hline (7) Has had an effect on the content of your notes & 3 & 13 & 22 & 17 & $5.06^{*}$ \\
\hline (8) Has had any effect on your practice & 3 & 13 & 29 & 10 & $12.22 * * *$ \\
\hline
\end{tabular}

A, agree; $\mathrm{D}$, disagree.

* $P<0.05, * * P<0.01, * * * P<0.001$.

(Insufficient numbers to compare other staff groups).

Questionnaires were sent by internal post to staff in February 1992 (three months after the Act came into force). Subsequent reminders were sent to those who had not returned the completed forms.

\section{Findings}

Seventy members of staff returned completed questionnaires ( $69 \%$ of the department). These comprised 16 out of 20 doctors $(80 \%), 30$ out of 44 nurses $(68 \%), 14$ out of 22 community psychiatric nurses $(64 \%), 4$ out of 5 psychologists $(80 \%)$ and 6 out of 11 occupational therapists $(55 \%)$.

\section{Awareness of the Act}

All of the sample were aware of the Act's existence; $66 \%$ had been told about the Act by their health team, $52 \%$ had told at least one patient about the Act and $15 \%$ had told more than 10 patients.

\section{Attitudes to patients being able to read their psychiatric bealth records}

\section{Effects on the records}

Of the sample, $81 \%$ agreed that the Act makes staff think more about what they write, $71 \%$ that it makes staff write less speculation in the notes, and $56 \%$ that it makes staff write better quality notes.

\section{Effects on patients}

Seventy-four per cent agreed it relieves patients' fears of what could be written in their notes, $50 \%$ were concerned that it may cause distress or anxiety to patients, and $19 \%$ agreed that it improves patients' compliance with treatment.

\section{Effects on staff}

Fifty-four per cent agreed it makes staff think more about their management of patients, $43 \%$ were concerned about patients using the information to take more legal proceedings, and $37 \%$ were concerned that it makes staff leave out important subjective opinion.

\section{Particular reservations (highest scoring)}

Notes

Of the sample, $18 \%$ had particular reservations about patients seeing psychotherapy notes.

\section{Patient groups}

Sixty per cent had particular reservations about paranoid patients seeing their psychiatric health records and $49 \%$ had particular reservations about psychotic patients seeing their notes. In total, $77 \%$ of staff had particular reservations about at least one category of notes or patients.

\section{Further rights for patients to see notes}

Of the sample, $34 \%$ felt patients should have further rights to see their health records beyond the present Act.

\section{Effect the Act has had on the staff}

Of staff, $48 \%$ felt the Act had had an effect on the contents of their notes, $42 \%$ on the presentation of their notes, $19 \%$ on their relationship with patients, and $12 \%$ on their care of patients.

\section{Differences between stafi groups}

See Table I. 


\section{Overall effect of the Act}

Of staff, $7 \%$ felt the overall effect of the Act was negative and $45 \%$ felt it was positive, $21 \%$ felt the Act had had no overall effect and $27 \%$ answered "don't know".

\section{Comment}

Studies following similar legislation introduced in Denmark in 1987 found that following access to health records there was no deterioration in the health of patients (Svendsen \& Toftegaard 1989). Uptake of the facility was limited but those patients who employed the legislation were satisfied with the results (Andersen \& Jorgensen, 1989).

In this country, Bernadt et al (1991) found that only half of psychiatric out-patients thought that a written summary provided helpful information, and about a quarter were upset by what they read. Another study suggested that the usefulness of notes may be diminished if subjective opinions and speculation are censored before reaching the page (McShane et al, 1992).

We set out to ask staff what they thought about the Act. Over the three months since the Act had come into force, only two patients in this hospital had asked to see their notes. By conducting our study at this early stage we were assessing staff attitudes after the Act had come into being but before staff came directly into contact with the legislation.

Staff clearly felt aware of the Act but many had only read or heard about it informally and had not discussed it with their health care teams. Furthermore relatively few had discussed it with their patients. This may be because staff are worried about patients making use of the Act although this is not borne out by the rest of our results. Alternatively some staff may not feel they have time to discuss the Act with patients or they may not feel fully confident about the details of the law.

Staff felt the Act would have a positive effect on the quality of notes. However, doctors felt the Act would make less difference than did nurses. Out of 64 questions in the questionnaire, there were eight significant differences between these two groups. When differences did occur, doctors generally felt the Act would alter practice less. Fewer than half of staff (doctors and nurses) were concerned about more legal proceedings. However, a relatively high proportion of staff felt that reading notes could either relieve or cause anxiety to patients (sometimes both). This probably reflects their feeling that different patients will react differently to seeing their notes.

The majority of staff had particular reservations about certain groups of patients. These reservations mainly concerned paranoid or psychotic patients. This may be because staff feel psychotic patients are less able to understand their notes or that they could suffer more stress from reading them.

Most staff felt the Act had had a generally positive effect. However, fewer staff felt the Act had actually changed their own behaviour. Less than one in seven felt it had affected their care of patients and only a half felt it had altered the way they write notes. This is at odds with warnings from The Royal College of Psychiatrists (1992) that the Act would have an important impact on record-taking practice.

In conclusion, it appears that most staff are in favour of the Act although many have reservations about it. Very few staff have discussed it formally with their health teams and this may be reflected in the low numbers who are discussing it with their patients or altering the way they write notes. It may be that staff have not yet realised that their notes will soon be under increased scrutiny and will continue to make little change until patients begin to use the Act.

\section{Acknowledgements}

We would like to thank Professor C. L. E. Katona for all his help and encouragement.

\section{References}

ANDERSEN, T. \& JoRgensen, G. (1989) Consequences of patients' access to hospital records. A prospective study at a somatic hospital. Ugeskr-Laeger, 151, 2428-2431.

Bernadt, M., GunNing, L. \& QuenstedT, M. (1991) Patients' access to their own psychiatric records. British Medical Journal, 303, 967.

McShane, R., Rowe, D. \& Julia, D. (1992) Will the information recorded in psychiatric notes change when patients have the right to read them? Psychiatric Bulletin, 16, 404-405.

The Royal College of Psychiatrists (1992) Access to Health Records Act 1990 College guidance. Psychiatric Bulletin, 16, 114-116.

Svendsen, A. B. \& TofteganRd, L. (1989) Access to psychiatric and child psychiatric case records in the Copenhagen County Hospital in Nordvang in 1987. Ugeskr-Laeger, 151, 1389-1392. 